\title{
Orthodontic-Surgical Treatment of Class III Malocclusion with Mandibular Asymmetry
}

\author{
Ana Zilda Nazar BERGAMO \\ Marcela Cristina Damião ANDRUCIOLI \\ Fábio Lourenço ROMANO \\ José Tarcísio Lima FERREIRA \\ Mírian Aiko Nakane MATSUMOTO
}

Department of Pediatric Clinics, Preventive and Community Dentistry, Ribeirão Preto Dental School, USP - University of São Paulo, Ribeirão Preto, SP, Brazil

\begin{abstract}
Class III skeletal malocclusion may present several etiologies, among which maxillary deficiency is the most frequent. Bone discrepancy may have an unfavorable impact on esthetics, which is frequently aggravated by the presence of accentuated facial asymmetries. This type of malocclusion is usually treated with association of Orthodontics and orthognathic surgery for correction of occlusion and facial esthetics. This report presents the treatment of a patient aged 15 years and 1 month with Class III skeletal malocclusion, having narrow maxilla, posterior open bite on the left side, anterior crossbite and unilateral posterior crossbite, accentuated negative dentoalveolar discrepancy in the maxillary arch, and maxillary and mandibular midline shift. Clinical examination also revealed maxillary hypoplasia, increased lower one third of the face, concave bone and facial profiles and facial asymmetry with mandibular deviation to the left side. The treatment was performed in three phases: presurgical orthodontic preparation, orthognathic surgery and orthodontic finishing. In reviewing the patient's final records, the major goals set at the beginning of treatment were successfully achieved, providing the patient with adequate masticatory function and pleasant facial esthetics.
\end{abstract}

Key Words: Class III malocclusion, facial asymmetry, orthognathic surgery.

\section{INTRODUCTION}

Class III skeletal malocclusion may result from mandibular prognathism, maxillary retrusion or a combination of both (1). Maxillary deficiency is more frequent, accounting for $60 \%$ to $63 \%$ of the causes of this type of malocclusion (2). Maxillary skeletal deficiency can also be associated with deficiency of the middle third of the face, confirmed by the contour of the zygomatic bone, orbital ridge and subpupillary area (3). Intraoral examination reveals increased axial inclination of the maxillary incisors and decreased axial inclination of the mandibular incisors in an attempt to mask the real maxillomandibular discrepancy (4). Bone discrepancy is reflected in the facial soft tissues, causing an unfavorable esthetic impact, which may be aggravated by the facial asymmetric present in most cases. Patients with these disharmonies are usually treated with a combination of Orthodontics and orthognathic surgery to improve occlusion and facial esthetics (5-7).

This report presents the treatment of Class III skeletal malocclusion with transverse alteration and facial asymmetry, whose magnitude demanded an orthodontic-surgical treatment for reestablishment of normal occlusion and adequate facial esthetics.

\section{CASE REPORT}

\section{Diagnosis and Etiology}

A male patient aged 15 years and 1 month came to the Orthodontics Clinic of Ribeirão Preto Dental School, University of São Paulo, Brazil, with main complaint of a palatally displaced maxillary right lateral incisor.

Facial analysis revealed accentuated facial asymmetry, slightly concave bone and facial profiles, 
maxillary hypoplasia, malar deficiency, and increased lower one third of the face. Clinical examination revealed Angle's Class III, subdivision right malocclusion, with narrow maxilla, left posterior open bite, deviation of the maxillary midline to the right and the mandibular midline to the left, and accentuated crowding in the maxillary anterior region, with palatal displacement of the maxillary right lateral incisor (Fig. 1).

The analysis of plaster models confirmed narrow maxilla with unilateral left posterior crossbite, negative dentoalveolar discrepancy in both arches (maxillary: $-9.0 \mathrm{~mm}$ and mandibular: $-2.0 \mathrm{~mm}$ ), Bolton discrepancy with $2.0 \mathrm{~mm}$ maxillary excess in total, being $0.2 \mathrm{~mm}$ in the anterior teeth, maxillary midline shifted $2 \mathrm{~mm}$ to the right, negative overjet of $5.0 \mathrm{~mm}$, absence of overbite, and palatally displaced maxillary right lateral incisor.

The lateral cephalometric radiograph revealed Class III skeletal malocclusion $\left(\mathrm{ANB}=-4.0^{\circ}\right.$ ), maxillary retrusion $\left(\mathrm{SNA}=78^{\circ}\right.$ ), slight mandible protrusion (SNB $=82^{\circ}$ ) in relation to the anterior skull base, concave bone profile $\left(\mathrm{NAPg}=-10.5^{\circ}\right)$, dolichofacial morphological type (facial axis $=39^{\circ}$ ) and predominance of vertical growth of the face $\left(\mathrm{SNGoGn}=36^{\circ}\right.$ and $\left.\mathrm{FMA}=34^{\circ}\right)$. The maxillary incisors presented increased axial inclination and were protruded in relation to their alveolar base (1. $\mathrm{NA}=30^{\circ}$ and $1-\mathrm{NA}=8 \mathrm{~mm}$ ), while the mandibular incisors presented decreased axial inclination and retrusion in relation to their alveolar base $\left(1 . \mathrm{NB}=16.5^{\circ}\right.$ and $1-\mathrm{NB}=3 \mathrm{~mm})$. The concave soft-tissue profile was accentuated with the retrusion of the upper and lower lips in relation to Steiner's $\mathrm{S}$ line $(\mathrm{LS}=-65 \mathrm{~mm} ; \mathrm{LI}=$ $-2 \mathrm{~mm}$ ) (Fig. 2).

Periapical radiographs showed malformed root of the mandibular left second premolar, narrow roots of the maxillary and mandibular incisors, indicating need of periodic radiographic follow up for control of root resorption. Panoramic radiograph (Fig. 2) showed horizontal resorption of the bone crests and the posteroanterior cephalometric radiograph of the face confirmed skeletal asymmetry.

\section{Treatment Objectives}

The main goals of the orthodontic-surgical treatment were to promote maxillary advancement and mandibular retrusion for correction of the dental relationship, Class III skeletal malocclusion and accentuated mandibular asymmetry with deviation to the left. The aim of the presurgical orthodontic preparation was to correct the dental disharmonies. Slow maxillary expansion and extraction of the maxillary first premolars on both sides were planned for correction of the maxillary midline shift and retroclination of the maxillary incisors, maintaining the anchorage with the use of Class II intermaxillary elastic mechanics. In the mandibular arch, proclination of the mandibular incisors was performed by increasing their axial inclination, thus accentuating the negative overjet in order to permit skeletal correction.
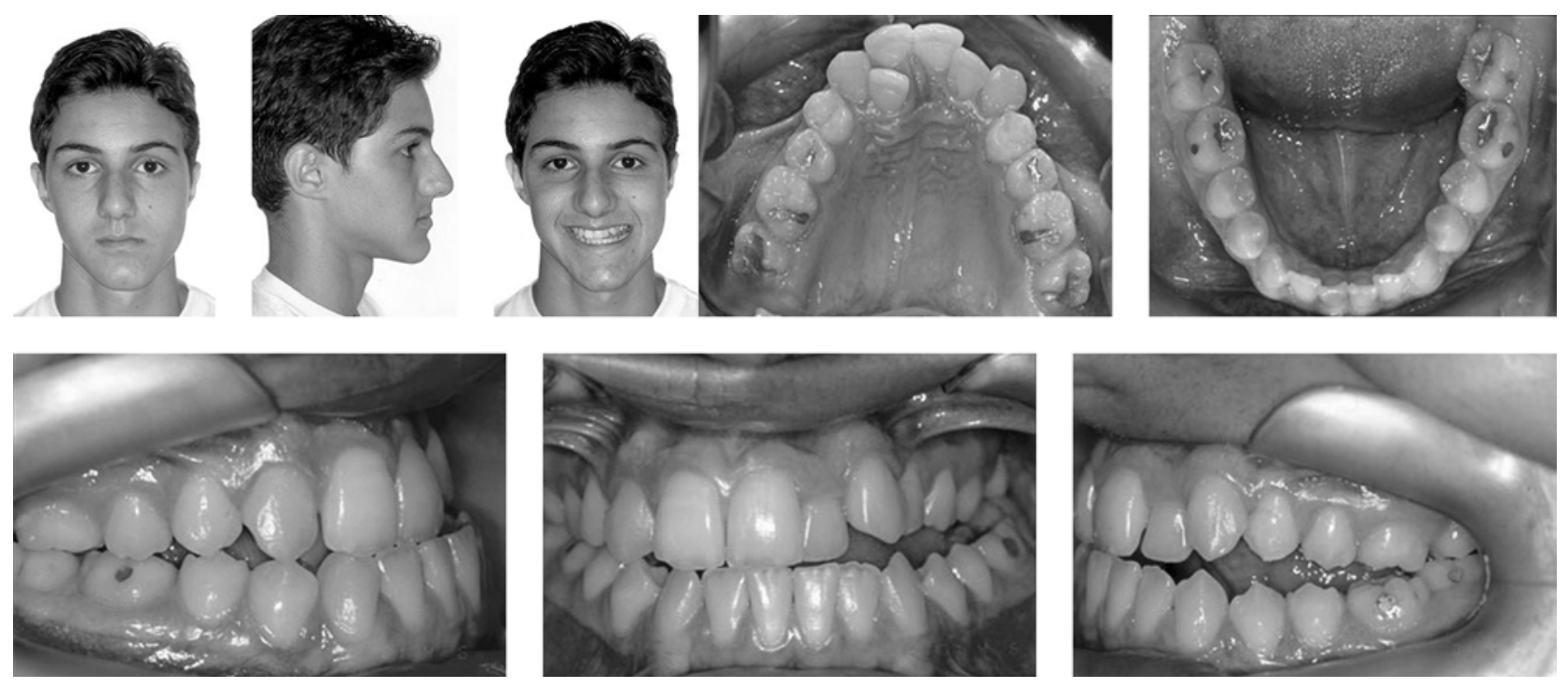

Figure 1. Pretreatment extraoral and intraoral photographs. 


\section{Treatment Progress}

Initially, a Haas palatal expander was fabricated to promote slow expansion of the maxilla with two activations per week. After assembling of the orthodontic appliance (Edgewise prescription - slot .022" x 0.28 "), extraction of the maxillary premolars on both sides was performed. A sequence of 0.014 " to 0.020 " stainless steel alignment and leveling archwires was used and correction of the maxillary midline based on the median sagittal plane was done to permit alignment and leveling of the maxillary right lateral incisor. Alignment and leveling of the mandibular dental arch (0.014" to 0.020 " archwires) was performed by moving the incisors buccally. Subsequently, retraction of the maxillary incisors was performed, maintaining the anchorage with Class II intermaxillary elastics.

The mandibular arch was slightly contracted by increasing the buccal root torque to the molars. In the maxillary arch, buccal root torque to the molars was decreased, thus contributing for correcting the transverse relationship between the dental arches. The intercuspation was checked by occluding the plaster models that were obtained periodically until satisfactory occlusion was attained for performing the surgery. After obtaining satisfactory intercuspation of the plaster models, soldered hooks were placed on a $0.019 \times 0.025$ stainless steel archwires in all inter-bracket spaces and the patient was forwarded to orthognathic surgery.
The third molars were extracted 6 months before the orthognathic surgery to permit bone formation in the extraction wounds. Figure 3 shows the presurgical orthodontic preparation.

The surgical procedure included maxillary
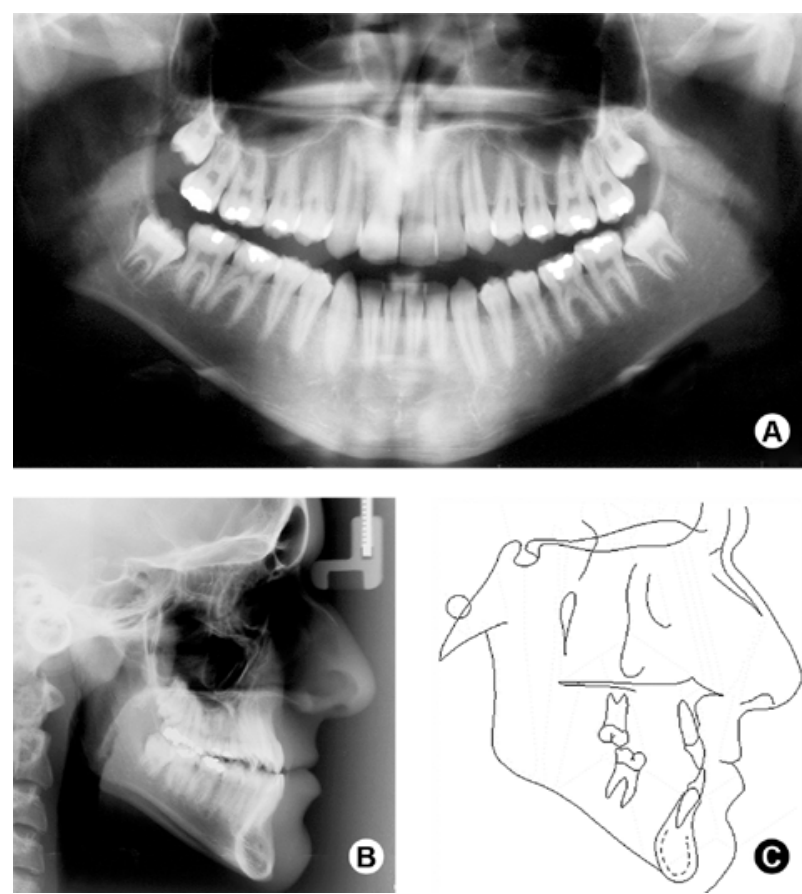

Figure 2. Initial panoramic radiograph (A), lateral cephalometric radiograph (B) and cephalometric tracings $(\mathrm{C})$.
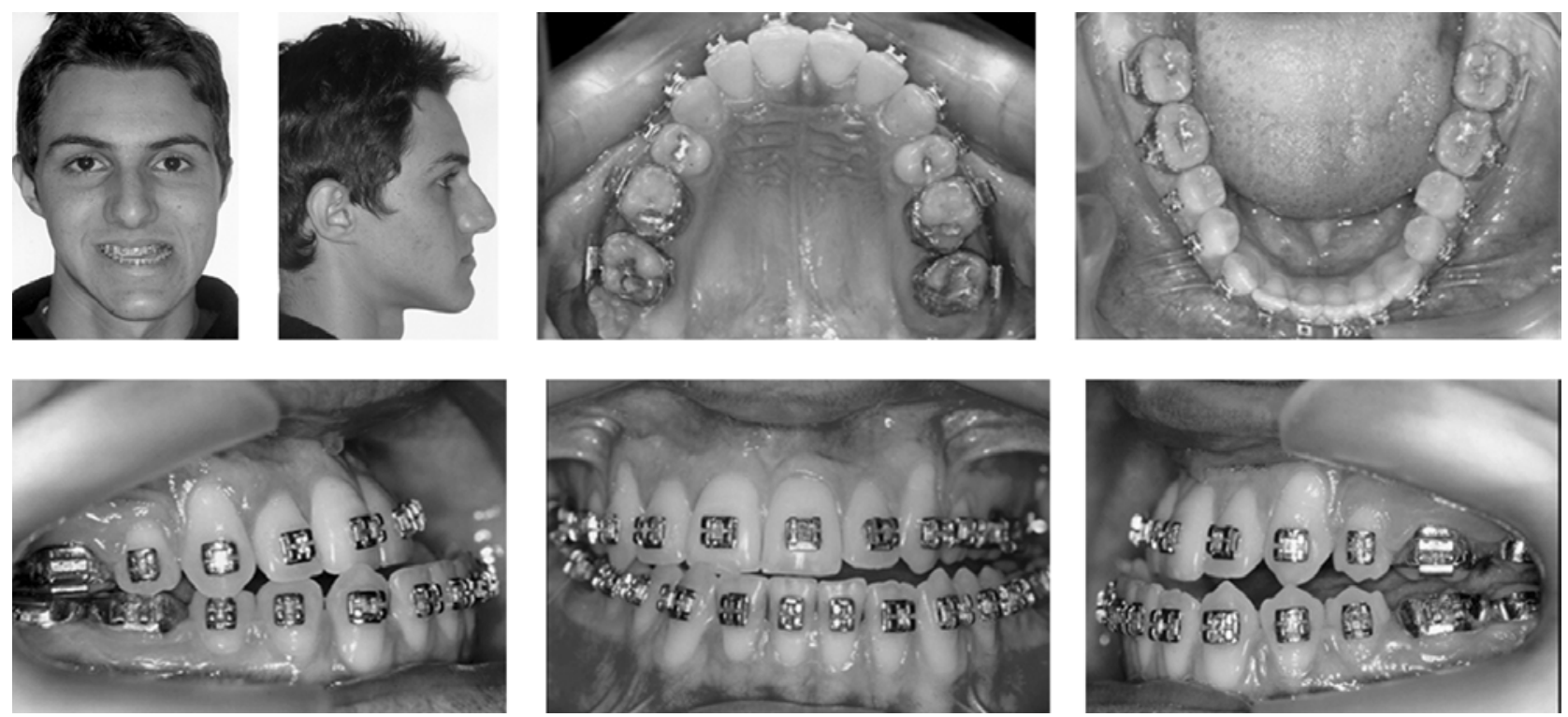

Figure 3. Intermediate extraoral and intraoral photographs. 
advancement and intrusion as well as retrusion and anticlockwise rotation of the mandible. Mandibular asymmetry was corrected with sagittal osteotomy of the mandible ramus, which permitted the adequate intercuspation of the dental arches with the repositioned maxilla and decrease of the angle of the mandibular plane, thus reducing the lower one third of the face.

Surgery was planned according to facial analysis, predictive cephalometric tracing, and preparation of the surgical guide. After surgery, the patient returned for orthodontic finishing for obtaining Class II molar relationship and Class I canine relationship, normal overjet and overbite and coincident midlines. After the active treatment phase, a wraparound-type retention plate was used in the maxillary arch and a stainless steel $3 \times 3$ lingual canine-to-canine retainer was placed in the mandibular arch.

\section{Treatment Results}

At the end of treatment, it was observed functional occlusion, normal overjet and overbite, and adequate intercuspation, with Class II molar relationship and Class I canine relationship, coincident midlines, normal lateral and protrusive excursions. Mandibular prognathism and asymmetry were eliminated and facial esthetics was considerably improved. The cephalometric measurements showed maxillary advancement, contributing to improve the patient's profile. The maxillary incisors were retruded and the mandibular incisors were protruded and had their axial inclination increased. Figures 4 and 5 show the results obtained with the orthognathic surgery and orthodontic finishing stage. Total and partial superimposition of initial and final cephalometric tracings revealed the changes occurred with the treatment (Fig. 6).

\section{DISCUSSION}

It is very important to understand the components of facial asymmetry in order to outline an accurate and effective treatment plan (7-10). The analysis of posteroanterior cephalometric radiographs determines if the asymmetry is related to the maxilla, mandible or both, in the sagittal or transverse directions, and if the anomaly is also associated with dental compensations.

Most studies have demonstrated that transverse dental compensation is correlated with skeletal asymmetry (8,10-12). Inclinations of the occlusal plane greater than $4^{\circ}$ and mentum deviations observed in the posteroanterior cephalograms are important characteristics to determine the presence and extension of facial asymmetry $(13,14)$.

The patient of this case presented significant facial asymmetry with occlusal plane inclination, mandibular asymmetry and mentum deviation to the left. Haraguchi et al. (14) and Severt and Proffit (15) have reported that in patients with dentofacial deformities with mandibular
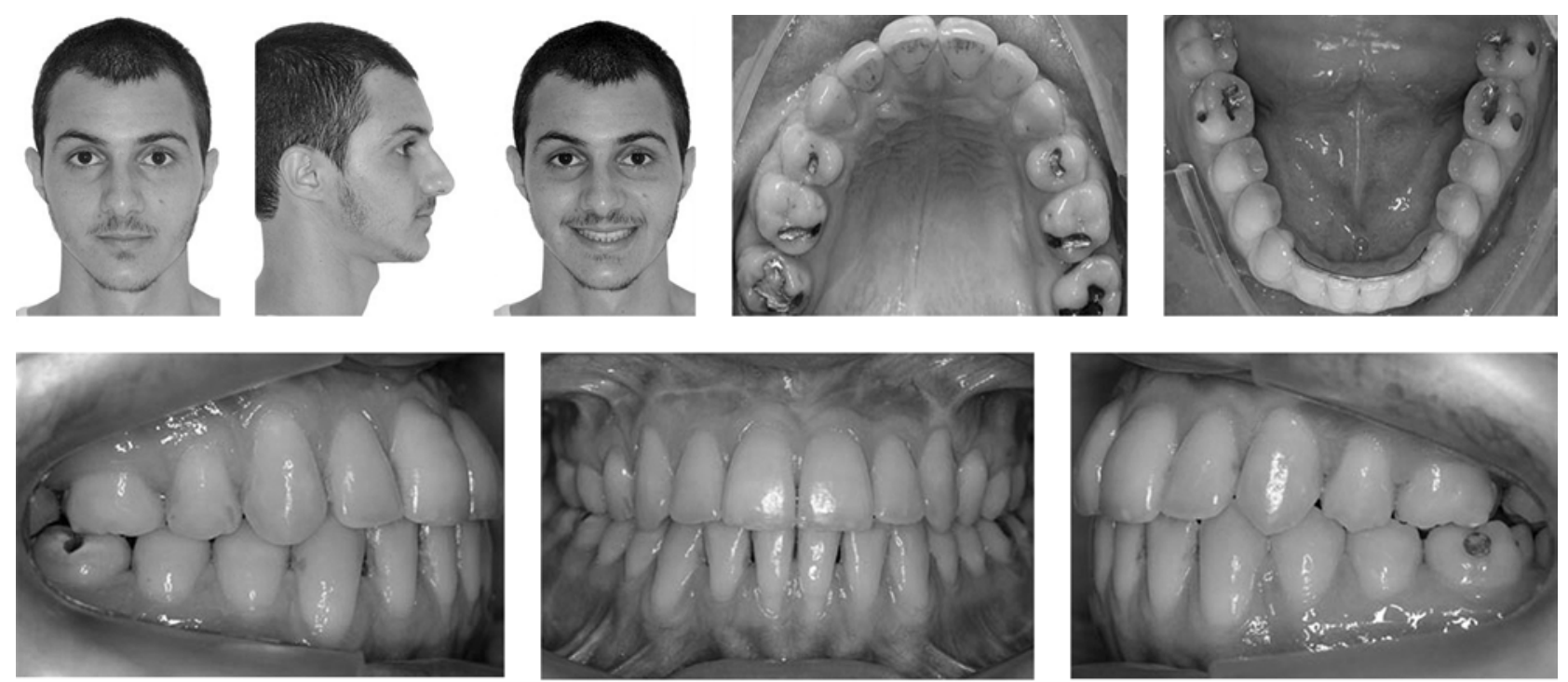

Figure 4. Final extraoral and intraoral photographs. 
deviation, lateral excursion to the left was present in over $85 \%$ of the studied population. According to Haraguchi et al. (14), the mandible is more asymmetrical than the maxilla because of its greater growth potential. While the mandible is a movable bone, the maxilla is rigidly connected to the adjacent skeletal structures by means of sutures and synchondroses.

The patient presented narrow maxilla associated with posterior crossbite in the left side. According to Haraguchi et al. (14), it is difficult to determine if the posterior crossbite is a consequence of narrow maxilla or if it simply results from the mandibular deviation. In the present case, posterior crossbite was treated with slow expansion in order to permit dentoalveolar remodeling. Surgically assisted disjunction was discarded due to the possibility of compromising the postsurgical stability (16). The maxillary right and left first premolars were extracted to correct the maxillary midline, dental compensations and negative dentoalveolar discrepancy. The inclination of the mandibular teeth was increased to promote satisfactory postsurgical interincisal relationship.

The objectives of the presurgical orthodontic treatment were achieved and only small corrections were necessary after surgery, obtaining adequate functional
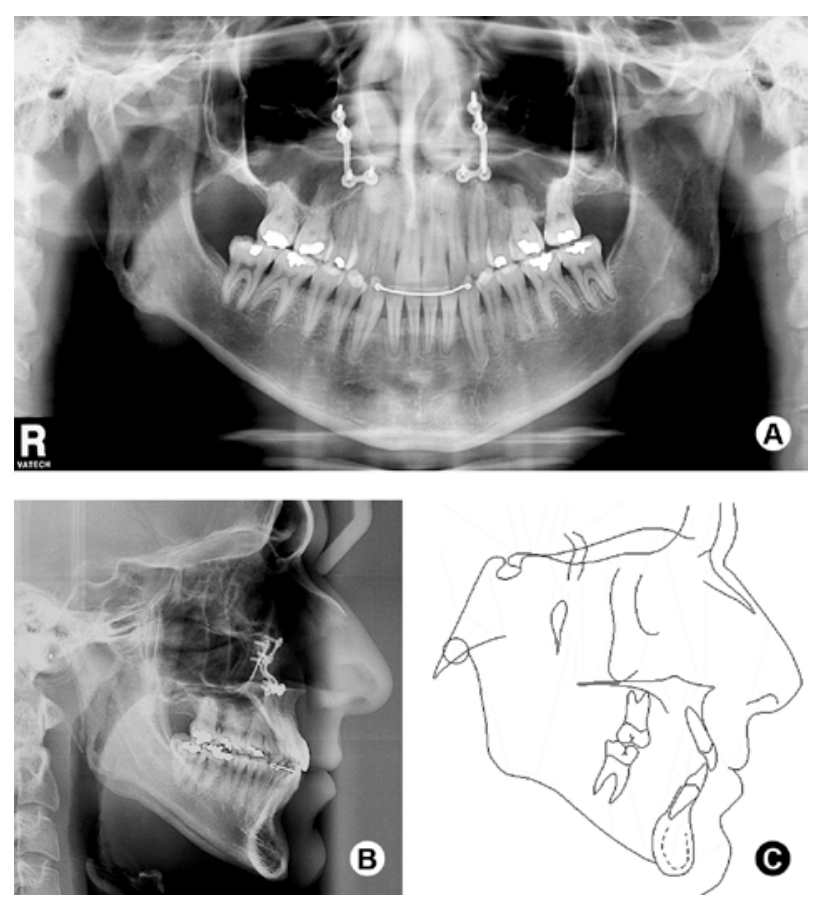

Figure 5. Final panoramic radiograph (A), lateral cephalometric radiograph (B) and cephalometric tracing $(\mathrm{C})$. occlusion and pleasant facial esthetics. The orthodontic treatment may provoke some undesirable alterations such as root resorptions. In the present case, root resorptions were not observed, in spite of the presence of roots with narrow root apices and anomaly of form in the mandibular left second premolar. There was gingival recession in the maxillary left canine. The causes of recessions may be predisposing factors, such as anatomy and morphology, and precipitating factors that induce or accelerate gingival inflammation and the occurrence of bone dehiscence (17-19). During the treatment, the patient received a gingival graft with success and the recession is currently under control.

Eighteen months after removal of the orthodontic appliance, the treatment can be considered as successful. The goals of the orthodontic-surgical treatment, namely having coincident the maxillary and mandibular midlines, correlating the mentum with the sagittal midline, leveling the lip commissures, giving a symmetric appearance to the maxillary canines, aligning and leveling the maxillary and mandibular teeth, and obtaining ideal anteroposterior, transverse and vertical occlusion, overjet and overbite, were completely achieved.

When the skeletal problem compromises the facial esthetics, the surgical-orthodontic treatment is the most indicated for patients who do not present facial growth potential and mainly for those who have facial asymmetry. A correct diagnosis and planning as well as an appropriate execution of the treatment plan are determinant factors for having success and long-term stability. In the case presented in this report, the orthodontic-surgical treatment was well indicated for correction of the Class III skeletal malocclusion and the patient's facial asymmetry, proving adequate masticatory function and pleasant facial esthetics.
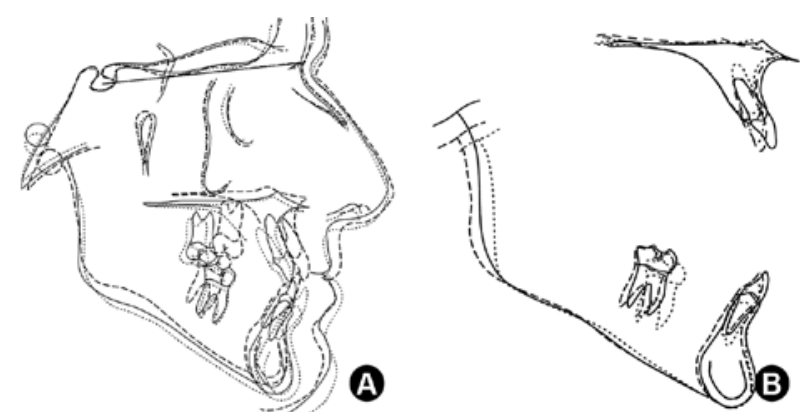

Figure 6. Total (A) and partial (B) superimposition of initial (full line), intermediate (dotted line) and final (traced line) cephalometric tracings. 


\section{RESUMO}

A maloclusão esquelética de Classe III pode apresentar diversas etiologias, sendo a deficiência maxilar a mais frequente. Discrepâncias esqueléticas podem ter impacto estético desfavorável, muitas vezes agravadas pela presença de assimetrias faciais acentuadas. Este tipo de maloclusão é geralmente tratado com a associação de Ortodontia e cirurgia ortognática para a correção da oclusão e da estética facial. Este relato de caso apresenta o tratamento de um paciente com 15 anos e 1 mês de idade, com maloclusão esquelética de Classe III, atresia maxilar, mordida aberta posterior do lado esquerdo, mordida cruzada anterior e mordida cruzada posterior unilateral, acentuada discrepância dento-alveolar negativa acentuada no arco maxilar e desvios das linhas médias superior e inferior. Ao exame clínico o paciente também apresentava deficiência maxilar, aumento do terço inferior da face, perfil ósseo e facial côncavos e assimetria facial, com desvio da mandíbula para o lado esquerdo. $\mathrm{O}$ tratamento foi realizado em três fases: preparo ortodôntico pré-cirúrgico, cirurgia ortognática e finalização ortodôntica. Analisando os registros finais do paciente, os principais objetivos estabelecidos ao início do tratamento foram alcançados com sucesso, promovendo ao paciente adequada função mastigatória e estética facial agradável.

\section{ACKNOWLEDGMENTS}

The authors are grateful to Dr. Eduardo P. Zanella for performing the orthognathic surgery.

\section{REFERENCES}

1. Delaire J. Maxillary development revisited: relevance to the orthopedic treatment of Class III malocclusions. Eur J Orthod 1997;19:289-311.

2. Turley P. Orthopedic correction of Class III malocclusion with palatal expansion and custom protaction headgear. J Clin Orthod 1988;22:314-325.

3. Arnett GW, Bergman RT. Facial keys to orthodontic planning. Part IAm J Orthod Dentofacial Orthop 1993;103:299-312.

4. Janson M, Janson G, Santana E, de Castro RC, de Freitas MR. Orthodontic-surgical treatment of Class III malocclusion with extraction of an impacted canine and multi-segmented maxillary surgery. Am J Orthod Dentofacial Orthop 2010;137:840-849.
5. Bishara SE, Burbey PS, Kharouf JG. Dental and facial asymmetries: a review. Angle Orthod 1994;64:89-98.

6. Posnick JC. Craniofacial and maxillofacial surgery in children and young adults. 3rd ed. Philadelphia:WB Saunders; 2000.

7. Decker, JD. Asymmetric mandibular prognathism: a 30-year retrospective case report. Am J Orthod Dentofacial Orthop 2006;129:436-443.

8. Hayashi K, Muguruma T. Morphologic characteristics of the dentition and palate in cases of skeletal asymmetry. Angle Orthod 2004;74:26-30.

9. Ko EW, Huang CS, Chen YR. Characteristics and corrective outcome of face asymmetry by orthognathic surgery. J Oral Maxillofac Surg 2009;67:2201-2209.

10. Sekiya T, Nakamura Y, Oikawa T, Ishii H, Hirashita A, Seto K. Elimination of transverse dental compensation is critical for treatment of patients with severe facial asymmetry. Am J Orthod Dentofacial Orthop 2010;137:552-562.

11. Kusayama M, Motohashi N, Kuroda T. Relationship between transverse dental anomalies and skeletal asymmetry. Am J Ortho Am J Orthod Dentofacial Orthop 2003;123:329-337.

12. Van Elslande DC, Russett SJ, Major PW, Flores-Mird C. Mandibular asymmetry diagnosis with panoramic imaging. Am J Orthod Dentofacial Orthop 2008;134:183-192.

13. Padwa BL, Kaiser MO, Kaban LB. Occlusal cant in the frontal plane as a reflection of facial asymmetry. J Oral Maxillofac Surg. 1997;55:811-816.

14. Haraguchi S, Takada K, Yasuda Y. Facial asymmetry in subjects with skeletal Class III deformity. Angle Orthod 2002;72:28-35.

15. Severt TR, Proffit WR. The prevalence of facial asymmetry in the dentofacial deformities population at the University of North Carolina. Int J Adult Orthodon Orthognath Surg 1997;12:171-176.

16. Proffit WR, Turvey TA, Phillips C. The hierarchy of stability and predictability in orthognathic surgery with rigid fixation: an update and extension. Head Face Med 2007;3:21.

17. Genco RJ. Current view of risk factors for periodontal diseases. J Periodontol 1996;67:1041-1049.

18. Leknes KN. The influence of anatomic and iatrogenic root surface characteristics on bacterial colonization and periodontal destruction: a review. J Periodontol 1997;68:507-516.

19. Melsen B. Biological reaction of alveolar bone to orthodontic tooth movement. Angle Orthod 1999;69:151-158.

Accepted December 21, 2010 